\title{
Just breathe: a review of sex and gender in chronic lung disease
}

\author{
Ranjani Somayaji ${ }^{1,2,3}$ and James D. Chalmers ${ }^{4}$ \\ Number 7 in the Series "Sex and gender in lung disease" \\ Edited by Jason Weatherald, Marc Humbert and Renata Riha
}

${ }^{1}$ Dept of Medicine, Cumming School of Medicine, University of Calgary, Calgary, Canada. ${ }^{2}$ Dept of Microbiology, Immunology and Infectious Disease, University of Calgary, Calgary, Canada. ${ }^{3}$ Dept of Community Health Sciences, University of Calgary, Calgary, Canada. ${ }^{4}$ Division of Molecular and Clinical Medicine, University of Dundee, Ninewells Hospital and Medical School, Dundee, UK.

Corresponding author: Ranjani Somayaji (rsomayaj@ucalgary.ca)

Shareable abstract (@ERSpublications)
Sex and gender differences impact lung diseases throughout the lifespan and are critical to
consider and incorporate into research and clinical care to optimise outcomes.
https://bit.ly/38hAhfY

Cite this article as: Somayaji R, Chalmers JD. Just breathe: a review of sex and gender in chronic lung disease. Eur Respir Rev 2022; 31: 210111 [DOI: 10.1183/16000617.0111-2021].

Copyright @The authors 2022

This version is distributed under the terms of the Creative Commons Attribution NonCommercial Licence 4.0. For commercial reproduction rights and permissions contact permissions@ersnet.org

Received: 2 May 2021 Accepted: 20 Aug 2021

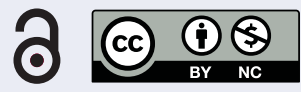

\section{Abstract}

Chronic lung diseases are the third leading cause of death worldwide and are increasing in prevalence over time. Although much of our traditional understanding of health and disease is derived from study of the male of the species - be it animal or human - there is increasing evidence that sex and gender contribute to differences in disease risk, prevalence, presentation, severity, treatment approach, response and outcomes. Chronic obstructive pulmonary disease, asthma and bronchiectasis represent the most prevalent and studied chronic lung diseases and have key sex- and gender-based differences which are critical to consider and incorporate into clinical and research approaches. Mechanistic differences present opportunities for therapeutic development whereas behavioural and clinical differences on the part of patients and providers present opportunities for greater education and understanding at multiple levels. In this review, we seek to summarise the sex- and gender-based differences in key chronic lung diseases and outline the clinical and research implications for stakeholders.

\section{Introduction}

Traditionally, much of our understanding of health and disease was derived through studies conducted on males - animal and human - without consideration for sex and gender [1]. Sex relates to biological characteristics whereas gender refers to socio-cultural and behavioural roles and aspects. Increasingly, evidence supports the impact of sex and gender on disease pathogenesis, risk and diagnosis, prevalence, severity, therapeutics and outcomes [2-6]. The male lung is larger than the female lung in persons of similar height, and males have greater lung capacity and flow volumes and rates [7]. This sets up the structural foundations for the differences in lung health and disease between the sexes. Gender-based factors have added implications on the occurrence, recognition and management across the spectrum of lung diseases. Herein, we review the role of sex and gender on lung health, detail how they impact common chronic lung diseases and delineate how we can better incorporate sex and gender into both the research and clinical realms as it relates to lung health.

\section{Sex and gender as a health determinant}

Sex refers to the primary and secondary sex characteristics inclusive of the anatomy and physiology which differentiates male and female organisms. The genetic differences in men and women beginning at conception lead to the sex differences in disease rates, presentations and response to therapies [8]. Gender refers to socially constructed norms that impose and determine roles, relationships and positional power for all people across their lifetime. Gender interacts with sex, the biological and physical characteristics that define women, men and those with intersex identities as defined by Global Health 50/50 [9, 10]. Although 
sex and gender are reciprocally and foundationally linked, it must be noted that gender also intersects with other factors such as age, ethnicity and race in matters of health [11-13].

Gender identities are not binary and gender-related attributes are fluid [14]. Gender is as important as sex when considering health as it influences behaviours across the spectrum [15]. Gender identity is characterised by self-perception as a woman, man or non-binary person and affects behaviours and feelings. Gender roles refer to the norms that are applied to people in society and this in turn can influence day-to-day activities and experiences (e.g., diet, physical activity, stress) and affects health status. Gender relations is defined by the interpersonal interactions that are shaped by a person's gender. The distribution of gender and associated characteristics in communities, institutions and society can readily impact health independently of sex $[8,16]$, and gender constructs can be used to examine health-related behaviours, access, use and outcomes. Thus, evaluation of gender in both research and clinical practice is very valuable in improving our understanding of health and disease in humans [17].

Sex and gender impacts on lung disease

Chronic pulmonary or lung disease has an estimated global prevalence of 544.9 million people. As of 2017 it is the third leading cause of death following cardiovascular diseases and neoplasms and deaths are increasing with time [18]. Chronic lung diseases account for $6.2 \%$ of deaths in females and $5.2 \%$ in males, of which chronic obstructive pulmonary disease (COPD) and asthma are the primary contributors [19]. Notably, there are clear sex-based differences in the prevalence of chronic lung diseases geographically with greater prevalence in high-income countries, and over time (figure 1). When thinking of lung disease in the context of sex and gender, bronchiectasis, pulmonary arterial hypertension (PAH) and lymphangioleiomyomatosis are well described to have a female predisposition [20], whereas idiopathic pulmonary fibrosis (IPF) predominantly affects males [21-23]. In other common lung diseases including asthma, COPD and bronchiectasis, although varied in their demographics and pathogenesis, there is a tendency for increased severity in adult females [6, 24].

Having emphasised the importance of sex and gender in health and disease, we will review their roles in the epidemiology, management and outcomes of key chronic lung diseases. The intersection of sex and gender with factors such as tobacco use [25] and circadian rhythms [26, 27], which vary by sex and gender and their relevance to lung disease, have been previously discussed [28]. As sex and gender are often used interchangeably, we will discuss concepts separately by sex and gender when data is available and summarise their roles by disease entity. Although not classified as a chronic pulmonary disease, we have also included a section on severe acute respiratory syndrome-coronavirus-2 (SARS-CoV-2) infection (coronavirus disease 20019: COVID-19) given its worldwide impact at present and the potential for post-infectious respiratory dysfunction.

Females, 1990

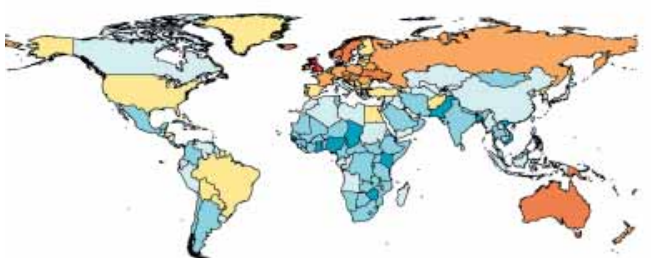

Males, 1990

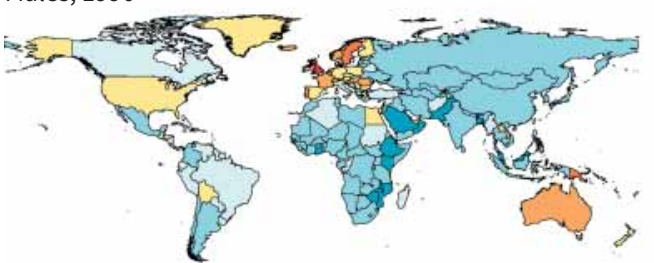

Females, 2017

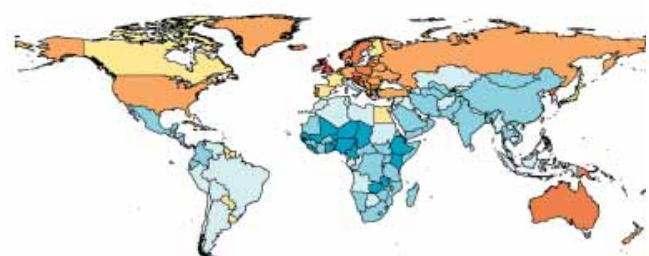

Males, 2017

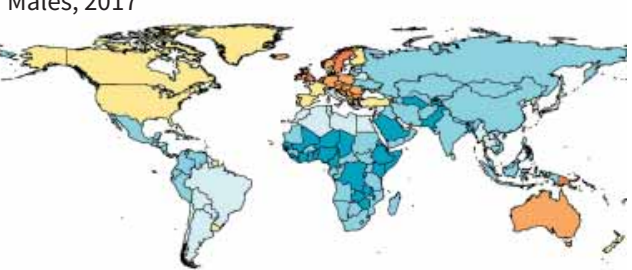

Prevalent cases per 100000 people (all ages)

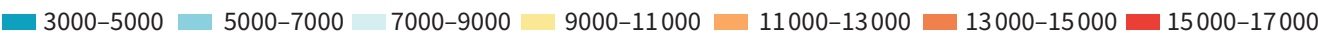

FIGURE 1 All-age and sex-based chronic respiratory disease prevalence by country in 1990 and 2017. Reproduced with permission from the Institute of Health Metrics and Evaluation Global Burden of Disease project [18]. 


\section{COPD}

The stereotype of a COPD patient has always been of an elderly man, as reflected in images such as the classic pink puffer/blue bloater [29, 30]. The impact of this stereotype is evidenced by the widespread use of the Fletcher-Peto curve of forced expiratory volume in $1 \mathrm{~s}\left(\mathrm{FEV}_{1}\right)$ decline, a curve derived entirely from studies of males [4].

The higher prevalence of COPD in males reflected a higher consumption of cigarettes among males in western countries during the early part of the 20th century, but has gradually changed as the disease has been more recognised and smoking habits have changed globally [31]. Smoking in females has grown in many high-income countries in particular and epidemiological estimates suggest COPD is now equally common in males and females in some regions [32]. The higher prevalence of COPD in females despite females smoking fewer cigarettes than males suggests that females may be more susceptible to the effects of cigarette smoke [33]. The contribution of non-cigarette risk factors to the global burden of COPD is large and growing [34-36]. The burden of indoor air pollutant exposure such as biomass fuel falls disproportionately on females and consequently some studies show that females account for up to two thirds of non-smoking COPD cases [34-37].

The perception of COPD as a male predominant disease may have contributed to underdiagnosis of COPD in females and therefore an underestimation of the burden of disease [38]. Illustrating the diagnostic bias in COPD, one study used a hypothetic case of cough and dyspnoea in a smoker to test diagnostic approaches in 192 randomly selected primary care physicians [38]. The age and sex of the case was varied, and COPD was given as the most probably diagnosis more often in males than females despite no clinical differences in presentation ( $58 \%$ versus $42 \%, \mathrm{p}<0.05)$. Consistent with this apparent bias, two studies conducted in North America and Europe both demonstrated that female smokers presenting with symptoms were less likely to be diagnosed with COPD, with spirometry and specialist referrals being less likely in females [39-41].

Females may also have worse outcomes than males. Hospitalisation and death from respiratory failure are reported to be more common in females with severe COPD than males [42, 43]. Smoking females have a steeper decline in lung function over time for a given exposure [44] and show a more rapid progression in CT lung density over time than males $[45,46]$.

In terms of clinical "phenotype", females report more severe dyspnoea, cough and are more likely to be affected by mental health problems and overall report lower scores in quality-of-life measures compared to males for a given $\mathrm{FEV}_{1} \%$ predicted, age, pack-years of smoking and extent of emphysema [47]. Females are more likely than males with COPD to experience suffer severe anxiety or depression including severe manifestations such as panic attacks [48]. Anxiety and depression impact perception of symptoms and are negatively associated with successful smoking cessation. Patients with anxiety and depression are less likely to complete pulmonary rehabilitation courses and anxiety and depression are also important risk factors for future exacerbations [48-50].

Although differences in exposures, occupations, societal roles, and biases in healthcare may account for many of the differences in clinical phenotype and outcomes between males and females, there is also strong evidence of true biological differences in lung pathology between sexes. Histologically, the disease may be different between the sexes with males having more emphysema and females having more small airway disease $[47,51]$. computed tomography (CT) studies also find males are likely to have more severe emphysema [45-47]. Experimental studies suggest a biological basis for these differences that may relate to the effect of sex hormones and anatomical differences between males and females, which are discussed in detail below [51]. In animal models, chronic exposure to cigarette smoke resulted in small airway disease and airflow obstruction in female mice while male animals receiving the same exposure developed more emphysema [51]. Reduction in female sex hormones through ovariectomy promoted greater emphysema similar to levels seen in male animals [51]. Similar results could be seen with the administration of tamoxifen, which blocks the oestrogen receptor, suggesting that oestrogen is central to these sex differences [51]. Less data is available on phenotypic differences in humans, but consistent with the animal data suggesting an airway-predominant phenotype in females, a 2010 US National Health and Wellness survey found $63 \%$ of those with chronic bronchitis were female [43].

Mendelian randomisation (MR) is a powerful tool to investigate the causal effects of variables on outcomes [52]. MR is a method of using variation in genes of known function to examine the causal effect of a modifiable exposure of disease in observational studies. In an MR study of the impact of age of menopause on lung function using UK biobank, vAN DER PLAAT et al. [53] found that early menopause was associated with a significantly lower risk of airflow obstruction. Meanwhile, an analysis of the role of 
testosterone levels and lung function also utilising UK biobank found higher $\mathrm{FEV}_{1}$ levels among individuals with higher testosterone after adjustment for multiple confounders including age, height, body mass index (BMI), smoking and multiple lifestyle factors [54]. A contribution of the X chromosome to COPD susceptibility is suggested by an increased risk of early onset COPD in females who smoke and also have a mother with COPD. The COPDGene study therefore identified female sex as a significant risk factor for early onset COPD [55]. These data suggest that oestrogen may contribute to declining lung function while testosterone may be protective, and therefore suggesting a contribution of sex hormones to the greater susceptibility of females to rapid $\mathrm{FEV}_{1}$ decline.

Multiple other mechanisms may be involved in the increased susceptibility of females to cigarette smoking, however, including anatomical factors such a smaller lungs and increased deposition of cigarette smoke in the airways [29, 42, 44]. Since the surface area for deposition is smaller, the concentration of particles per unit of surface area will be greater. Females may also mount a greater inflammatory response than males with an analysis of the proteome of bronchoalveolar lavage from females and males with COPD showing significant differences including downregulation of the lysosomal pathway and upregulation of oxidative phosphorylation in females [56].

These data suggest the need to emphasise the importance of smoking cessation and prevention initiatives targeting females, as a population at high risk of COPD development [42, 57]. This includes discussions around the increasing use of electronic cigarettes [58]. In terms of the treatment of COPD once established, there are no recommendations for different approaches to male and female patients [59]. Bronchodilator treatment appears to be equally effective in terms of improved lung function and improved quality of life in males and females [59-61]. A secondary analysis of the FLAME study found no differences in response to dual bronchodilators compared to inhaled corticosteroid (ICS)/long-acting $\beta 2$ agonist (LABA) in males and females [60]. A small number of studies suggest superior bronchodilator responses in females compared to males including data from the Lung Healthy Study of Ipratropium, and a pooled analysis of trials of indacaterol/glycopyrronium compared to ICS/LABA, long-acting muscarinic antagonist or placebo showed greater improvements in health status, dyspnoea, rescue medication use and symptoms in women $[60,62,63]$. Less data is available on other treatments for COPD and how response varies by sex. A study by HAN et al. [64], found no difference in treatment response with azithromycin by sex. There are similarly no data to suggest that interventions such as pulmonary rehabilitation are more or less effective based on sex or gender [65].

\section{Asthma}

Asthma demonstrates a sex disparity which changes from childhood to adulthood [66, 67]. In childhood, asthma is much more common in boys than girls; however, by the time they become adults there is a reversal with more adult females than males. For instance, US data from 2018 shows that the prevalence of asthma was $8.4 \%$ in males and $5.5 \%$ in females younger than 18 , reversing to $6.1 \%$ in males and $9.8 \%$ in females aged $>18$ years [68]. In keeping with the differences in burden of disease at the two different stages of life, boys are twice as likely as girls to be hospitalised for an asthma exacerbation in childhood, but the reverse is true in adulthood with females then three times more likely to be hospitalised for asthma events [69-71].

The consistent demonstration that asthma prevalence and severity shift around the time of major changes in hormone levels suggests a significant role for sex hormones in the pathogenesis of asthma [66]. Early menarche is associated with an increased risk of asthma and asthma prevalence, which then decreases around the time of the menopause [72, 73]. Although this is true of asthma prevalence, there is little evidence to suggest that the onset of menopause results in reduced asthma symptoms in patients with established asthma and indeed the European Community Respiratory Health Surveys cross-sectional study reported an increase in asthma symptoms in females during menopause [74]. Further evidence of sex hormone impacts on asthma symptoms are demonstrated by approximately $40 \%$ of females with asthma reporting pre- or peri-menstrual worsening of symptoms associated with decreased peak expiratory flow and increased use of reliever medications [75-77].

There is evidence of variation in T helper 2 (Th2) and eosinophilic inflammation with the menstrual cycle, and particularly an increase in sputum eosinophilia in the pre-menstrual phase of the cycle [75-78]. Reports of the impact of oral contraceptives on asthma symptoms and severity are conflicting, but a well-conducted 17-year population-based study from the UK suggested a reduced risk of severe asthma with contraceptive use [79]. Pregnancy is well known to affect asthma symptoms in some individuals, although it is unpredictable whether pregnancy will be associated with improved, worsened or stable asthma symptoms $[80,81]$. It is commonly quoted that one third will improve, one third will worsen and 
one third will remain stable. This unpredictability suggests that sex hormones may have distinct effects on different asthma phenotypes, with asthma known to be a highly heterogeneous disease [82-85].

Experimental studies (especially in mice) suggest an important role for sex and sex hormones in asthma. Baseline airway hyperresponsiveness is greater in male versus female mice and male mice also have increased vagal nerve responses when challenged with methacholine [86, 87]. These effects can be reversed by gonadectomy and reproduced by exogenous androgens. Asthma is characterised by infiltration of eosinophils, increased IgE and increased expression of cytokines such as interleukin (IL)-5, IL-4 and IL-13, [88, 89]. An established model of inducing airway inflammation and airway hyperresponsiveness in mice is the use of exposure to ovalbumin. Using this approach, it has been shown that ovariectomised mice had reduced IL-5 levels and eosinophil recruitment after ovalbumin exposure compared to control mice [90]. Treatment with a synthetic oestrogen before ovalbumin treatment restored the excessive eosinophil recruitment suggesting a direct effect of oestrogen in promoting eosinophil recruitment to the airway.

Results regarding male sex hormones are less clear. Castration of male mice resulted in an increase in ovalbumin induced eosinophil (and lymphocyte) accumulation compared to sham-operated controls, but with house dust mite challenge it was shown that dehydroepiandrosteone (a precursor of testosterone) reduced eosinophilia, IL4 and Il-6 levels [91].

Differences between challenged female and male mice across various studies show increased IL-5 and IL-13 release from type 2 innate lymphoid cells, increased serum IgE, and increased alveolar macrophages and dendritic cell numbers in female animals [92-96]. Increased release of IL-17A from Th17 cells and associated increased neutrophilic inflammation has also been reported [97]. This latter effect is also evident in humans with severe asthma where females had significant increased IL-17A release from Th17 cells compared to males with evidence that this was directly regulated by oestrogen and progesterone [98, 99].

Taken together, these data suggest importance differences in the underlying biology of asthma between males and females. Female sex has been identified as a risk factor for low health-related quality of life in asthma [100]. Females have a higher frequency of non-allergic asthma than males and have a higher frequency of healthcare contacts and hospitalisations indicating more severe asthma, which is also reflected in 2011 data from the Centers for Disease Control and Prevention showing a 30\% increase in mortality from asthma in females compared to males [101]. Severe asthma cohorts consistently show a female preponderance; for example, the recent report of the UK Severe Asthma Registry ( $n=2225$ patients from 15 severe asthma centres) reported $62.4 \%$ females [102]. Males have been most adversely affected during the COVID-19 pandemic in terms of mortality [103-105], but a recent report of hospitalised patients from France with asthma and COVID-19 reported 70\% females [106], and the Australian Mepolizumab registry recently reported data from severe asthma patients requiring biologics indicating 58\% were female [107]. The consistent message is that in cohorts of patients with asthma with high disease burden, there is invariably an excess of female patients. A report from the Severe Asthma Network in Italy registry ( $n=1123$ ) found that two thirds of severe asthma patients were female and reported increased obesity and gastro-oesophageal reflux as well as increased age of onset in females [108]. Females had greater disease burden with more hospitalisations and worse asthma control while males had greater markers of T2 inflammation such as eosinophilia and IgE levels. These findings are consistent with the clinical observation of a distinct phenotype of severe asthma with low Th2 inflammation and obesity that is predominantly seen in females [109].

What are the implications for treatment? Males and females with asthma may have different proportions of treatable traits, but in general the same therapies are effective in both sexes [110]. There is no evidence of a differential response to ICS overall, but as noted T2 low disease that is less corticosteroid responsive may be more frequent in females. Interestingly, in the previously mentioned Australian study of mepolizumab response, males were less likely to be super-responders [107]. Most large phase 3 studies of biologic agents do not present response data by sex. Treatment approaches in asthma and particularly severe asthma should acknowledge that females may have worse outcomes and a higher risk of having T2-low asthma.

\section{Bronchiectasis and cystic fibrosis (CF)}

For reasons that are unknown, bronchiectasis not due to CF is a female predominant disorder in the majority of countries worldwide [111-113]. Data from the USA, Europe, Asia, Australasia and South America shows an excess of females ranging from modest (55 versus 45\%) [114-119] to large (71 versus 29\%) in the Australian bronchiectasis registry) [120]. This difference is evident across all ages and although bronchiectasis is caused by a wide range of different aetiologies [121], the female preponderance is evident across the majority. An important outlier in terms of sex differences is the India bronchiectasis 
registry, which reported that $57 \%$ of patients were male [122]. The dominant cause of bronchiectasis in India was tuberculosis, which is reported more frequently in males [123].

Bronchiectasis is defined by permanent dilation of the bronchi and is a syndrome of chronic cough, sputum production and recurrent respiratory infections that can be caused by multiple different underlying diseases [124]. A number of the underlying causes of bronchiectasis are more common in females including non-tuberculous mycobacterial infection [125] and rheumatoid arthritis, but idiopathic and post-infective bronchiectasis, where an underlying disorder has not been identified, is also more common in women. Quint et al. studied bronchiectasis prevalence, incidence, and mortality in the UK between 2004 and 2013 using the Clinical Practice Research Datalink, a database of 660 primary care practices in the UK. They found 58.5\% of patients were female and that the prevalence of bronchiectasis has increased during that period with the prevalence in men rising from 301.2/100000 in 2004 to 485.5/100000 in 2013 and the prevalence in women rising from $350.5 / 100000$ in 2004 to 566.1/100000 in 2013 [126]. It is not clear if this is a true increase or relates to increased use of CT scanning and addressing historical underdiagnosis. In their study of Medicare recipients (USA federally funded health insurance, primarily for those aged over 65), HenkLE et al. [127] found that 70\% of patients newly diagnosed with bronchiectasis were female.

Why bronchiectasis is more frequent in females than males is not known, but differences in airway responses between males and females suggest possible mechanisms [128]. Bronchiectasis is associated with small airway inflammation and the previously noted propensity for females to experience small airway inflammation in response to environmental toxins may therefore be relevant [51]. In addition, the genetic conditions primary ciliary dyskinesia and CF demonstrate the key role of mucociliary clearance in the development of bronchiectasis [129, 130].

Non-CF bronchiectasis has been described as one of the most neglected diseases in respiratory medicine, with very few studies conducted exploring its pathogenesis. Much of our understanding of sex and gender impacts on bronchiectasis come from CF. Given the inheritance pattern, CF has an equal prevalence in males and females, but the outcomes remain disparate and there remains a gap despite the dramatic advancements in therapeutics and survival of persons with CF over the last decades.

The CF survival "gender gap”, first reported in the 1990s [131-133], was observed by clinicians in the 1980s with girls with CF coming into hospital more often and, in contrast to the general population where women live 6-8 years longer than men, the girls died sooner [134]. A population-based analysis of the US CF registry encompassing 21000 people in 1997 demonstrated that the median life expectancy for females was 25.3 years compared to 28.4 years for males [135]. This gap has persisted even after the advent of novel therapies to correct the inherent genetic mutations seen in CF as a 2014 study of 30000 persons with CF in the USA following the availability of ivacaftor (a highly effective CF transmembrane conductance regulator (CFTR) modulator) demonstrated that the median survival of females was still less than that of males (36.0 and 38.7 years respectively) including after accounting for multiple clinical factors [136]. Notably, in this time, some published reports have refuted the gender gap in CF citing that improved therapies may be narrowing the observed difference [137-140].

Differences in severity and outcome have been reported in non-CF bronchiectasis as well [141]. An analysis of the European Bronchiectasis Registry that included 11204 patients, but which has not yet been peer reviewed found that males had more co-morbidities, were more likely have co-existing COPD, worse $\mathrm{FEV}_{1}$ and had a higher severity of disease using the bronchiectasis severity index [141, 142]. Consistent with other airway diseases, however, quality of life was worse in females [141, 143]. The reasons for this require further study. Interestingly, GuAN et al. [144] found that females had more severe cough and were more sensitive to capsaicin-induced cough than males and several studies have found greater depression and anxiety in females with bronchiectasis, which impacts on quality of life [144-146]. The overlap with COPD and asthma is clearly an important confounder in bronchiectasis studies [147]. It is unclear if the excess of COPD in men reflects diagnostic bias, as COPD is classically consider a "male disease" or reflects a genuine difference in phenotype.

Regardless of controversy, multiple studies have been undertaken to evaluate the mechanisms leading to the gender disparity in CF with a focus on sex hormones, although other hypotheses include immunologic, nutritional or anatomic (morphometric) differences. From a microbiology and infection perspective, studies have demonstrated that females acquire Pseudomonas aeruginosa infection, one of the most prevalent CF pathogens, at earlier ages (median 9.5 years versus 11.2 years in males), have earlier conversion of the pathogen to a more virulent (and antibiotic-resistant) mucoid form, and 
experienced more rapid lung function decline and worsened outcomes following infection [136 148150]. In vitro experiments support these findings as oestrogen modulates the biofilm formation in $P$. aeruginosa by way of lactoferrin (activated protein kinase) suppression. Male CF mice that are exposed to exogenous oestrogen also have a resulting decrease in lactoferrin and consequent increase in $P$. aeruginosa burden in the lungs. Earlier acquisition of infection in females extends beyond $P$. aeruginosa to other common CF pathogens (i.e., Staphylococcus aureus, non-tuberculous mycobacteria (NTM)), often occurring prior to puberty (suggestive of sex-hormone-independent effects), with a resulting greater mortality [136]. Increased risk of NTM infection in females has been described in non-CF cohorts in primarily older and post-menopausal age groups and has been attributed to genetic causes as in one study documenting $36 \%$ of cases had one copy of a CFTR disease-causing mutation or other nutritional and morphometric factors [151-153].

Sex hormones have been identified to influence factors that directly play a role in CF lung disease including airway epithelial ion (sodium and chloride) transport [154, 155], airway surface liquid (ASL) volume [156], inflammatory mediators implicated in airways infection [149] and mucociliary transport [157]. Although these factors may not be directly causative of poorer outcomes in females, oestrogen is noted to decrease chloride transport by way of calcium-mediated chloride transport with resultant decreased ASL volumes in females with CF [156]. As altered mucociliary clearance is a hallmark feature of CF airways disease, this mechanism may in part explain why females are at greater risk for airways infection by CF pathogens [136]. Variation in lung health also appears to correlate with the phases of the menstrual cycle, lending further credence to the sex hormone hypothesis in CF. Data suggests that lung function is greatest during the luteal phase of the ovulatory cycle in women, which is consistent with the patterns of healthy women [158, 159]. Pulmonary exacerbations are more frequent during ovulation, a time with high oestrogen levels, and risks may be mitigated when oral contraceptives are used [149]. Puberty is another key time point for exacerbations as adolescent females have greater exacerbation rates as compared with adult males [160]. Limited data regarding menopause effects on CF lung disease exists in part due to the life expectancy in this population; improving survival in the advent of highly effective therapies may enable us to evaluate older CF cohorts in time. Similarly, there is little data regarding the impact of pregnancy on CF lung disease though no long-term deleterious consequences on lung health or mortality are apparent [161-163].

As sex hormones do not fully explain the gender gap, differences in host immunity and response are postulated as another possibility. Studies of the innate immune response have demonstrated that oestrogen effects include inhibition of IL-8 production in vitro in CF bronchial epithelial cells and of the respiratory burst in neutrophils, both of which can impair neutrophil function and inflammatory responses in women [164-166]. Another theory relates to the chromosomal differences in immunity genes. As women have a greater number of immunity genes on the $\mathrm{X}$ chromosome, this may mediate infection susceptibility variably based on the type of infection. As the genes promote pro-inflammatory responses that are very useful for acute infections, these same responses may in turn be a disadvantage in the context of chronic infections [134]. A study of microRNAs, which are small nucleic acid chains that inhibit specific genes, identified that levels of one called miR885-5P were higher in girls than in boys with CF [167]. The miR885-5P molecule inhibits the action of Ras-related C3 botulinum toxin substrate 1 (RAC1), which is a protein that regulates CFTR, and this is a particularly timely finding given the recent approvals of CFTR-based therapies. In particular, a combination CFTR compound which was demonstrated to be highly effective for the vast majority of persons with CF was approved in fall 2019 by the US Federal Food and Drug Administration [168, 169]. As higher RAC1 levels are likely to lead to a greater response, it is possible that women may have a poorer response based on increased miR885-5P levels, but this remains to be studied further [167]. Figure 2 summarises some of the sex-related differences in biology as they relate to the four components of the vicious cycle of bronchiectasis (infection, structural lung disease, inflammation and immunity and mucociliary clearance and epithelial function).

The differences in the lived experience and outcomes for males and females with CF stem from an integrated effect of both sex- and gender-associated factors and begin early on [170]. Multiple reports have identified that females are diagnosed later than males both in childhood and adulthood [171-173], which affects age-based prevalence estimates, and compounded with other disease differences [148, 174], likely contributes to worsened health outcomes $[175,176]$. The diagnostic lag in in children and adults may be related to decreased recognition of respiratory symptoms and unconscious gender bias by healthcare providers towards females [171-173]. Additionally, gender-related factors that disadvantage young females with CF include illness-related worries and poor coping, decreased quality of life, greater depression, discouragement of treatment, and acceptance of being underweight [177-184]. 
Increased frequency of $P$. aeruginosa infection

Mucoid conversion of $P$. aeruginosa

Increased susceptibility to NTM infection

Smaller lungs
More rapid lung function decline with cigarette smoke
Increased exposure to household pollution
Small airways disease

Female sex hormones promote eosinophilia and Th2 responses

Increased IL-17A release from Th17 cells

Increased propensity to autoimmunity

Increased susceptibility to oxidative damage by tobacco

Decreased airway surface liquid

Increased mucus cell hyperplasia and increased mucus production by female sex hormones

Reduced ciliary beat frequency
Increased severity of some infections (e.g. SARS-CoV-2)

Infection

\section{Greater propensity to emphysema}

Increased baseline airway hyperresponsiveness

Structural

lung disease

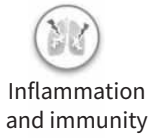

Male sex hormones suppress eosinophilia, IL-4 and IL-6

levels in the airway

and immunity

Testosterone increases CFTR expression leading to

mucus hydration

FIGURE 2 Postulated mechanisms by sex for chronic lung disease. Pink: female; blue: male. CFTR: cystic fibrosis transmembrane conductance regulator; IL: interleukin; NTM: non-tuberculous mycobacteria; $P$. aeruginosa: Pseudomonas aeruginosa; SARS-CoV-2: severe acute respiratory syndrome-coronavirus-2.

In terms of therapy, CF and bronchiectasis guidelines do not present separate recommendations for males and females and there is little evidence of differential response to therapy $[185,186]$. The therapy with the strongest evidence base in non-CF bronchiectasis is long-term macrolide therapy, which reduces exacerbations by approximately 50\% [187]. In an individual participant meta-analysis of the trials of long-term macrolide therapy in bronchiectasis, macrolide therapy reduced exacerbation frequency in both sexes, with the suggestion of a greater reduction in females (rate ratio 0.43; 95\% CI 0.29-0.62) compared to males (rate ratio 0.59; 95\% CI 0.35-0.99) [187]. The differences were similar for time to next exacerbation, with rate ratio 0.38 (95\% CI 0.27-0.55) for females compared to 0.57 (95\% CI 0.34-0.95) for males. Consistent with this, females had a clinically meaningful 5.6-point improvement in the St George's Respiratory Questionnaire which was less pronounced in males (1.5 points; 95\% CI -2.3 to 5.3) [187]. In contrast, males appeared to be more responsive to inhaled dry powder mannitol with a rate ratio for exacerbations of 0.65 (95\% CI 0.46-0.93) in males and 0.86 (95\% CI 0.66-1.13) in females [188]. Further research is needed to establish if these reflect true differences in treatment response, but as it stands the approach to therapy is not markedly different between sexes.

\section{Other lung diseases}

A variety of other lung diseases demonstrate sex (and gender) differences in prevalence and clinical outcomes and will be briefly reviewed. IPF represents the most common entity of the interstitial lung and has a greater prevalence in males [189]. Although female sex is predictive of improved outcomes including survival [190-192], females have a greater symptom burden and worse health-related quality of life with IPF [193]. Limited data in the form of animal models or human studies to understand this dimorphism exists, but to date have suggested an adverse role of testosterone in this disease [194]. PAH is a progressive disease involving the lung vessels and has a greater prevalence and survival in females, and termed the "oestrogen paradox" given the contrast in susceptibility and outcomes [195-197]. Both animal and human studies have identified that 17B-estradiol may have direct and indirect effects in PAH [195], although sex differences in response to treatment are unknown. Sleep-disordered breathing (SDB) is characterised by dysfunctional airway regulation resulting in poor sleep quality and is implicated in a variety of disease risks [198]. Females are less likely to seek medical care, and report differing symptoms of sleep apnoea leading to lesser recognition or diagnosis [199, 200]. Although middle-aged males are thought to be the most vulnerable to SDB mortality and disease outcomes, susceptibility may increase in females based on body mass, as well as at specific stages such as pregnancy (including adverse neonatal outcomes) [201] and menopause [199, 200]. Data suggest that the biologic pathways involved in the aetiology of SDB differs between males and females [202]. Further, as SDB is a risk factor and presents concurrently with many conditions that affect females, there needs to be greater study into and consideration of this in female health [28, 200]. A summary of the impacts of sex and gender on chronic lung disease are shown in table 1. 


\begin{tabular}{|c|c|c|c|}
\hline Disease & Epidemiology & Phenotype/prognosis & Treatment \\
\hline Asthma & $\begin{array}{l}\text { Childhood boys }>\text { girls } \\
\text { Adulthood females }>\text { males } \\
\text { Severe asthma females }>\text { males }\end{array}$ & $\begin{array}{l}\text { Females have more non-allergic asthma } \\
\text { Higher frequency of hospitalisation in females } \\
\text { Worse quality of life in females }\end{array}$ & $\begin{array}{l}\text { Females may have more Th2 low } \\
\text { disease }\end{array}$ \\
\hline Bronchiectasis & $\sim 70 \%$ female globally & $\begin{array}{l}\text { Males have worse lung function and more severe } \\
\text { disease } \\
\text { Worse symptoms, increased cough in females } \\
\text { High frequency of } P \text {. aeruginosa and NTM in females }\end{array}$ & $\begin{array}{l}\text { No sex-related differences } \\
\text { Increased awareness of NTM in } \\
\text { females }\end{array}$ \\
\hline COPD & $\begin{array}{l}\text { Classically male disease but } \\
\text { prevalence increasing in } \\
\text { females } \\
\text { Diagnostic bias in favour of } \\
\text { males }\end{array}$ & $\begin{array}{l}\text { Females have more small airways disease, less } \\
\text { emphysema, worse quality of life, more anxiety and } \\
\text { depression and more rapid lung function decline }\end{array}$ & $\begin{array}{l}\text { No sex-related differences in } \\
\text { treatment }\end{array}$ \\
\hline CF & $\begin{array}{l}\text { Equal disease prevalence } \\
\text { (genetic) } \\
\text { Diagnostic bias in favour of } \\
\text { males }\end{array}$ & $\begin{array}{l}\text { Decreased survival in females } \\
\text { Greater rate of pulmonary exacerbations (post-puberty) } \\
\text { Earlier acquisition of } P \text {. aeruginosa in females (and } \\
\text { greater lung function decline) } \\
\text { Worse quality of life, greater depression in females }\end{array}$ & $\begin{array}{l}\text { Discouragement of treatment, } \\
\text { acceptance of being underweight } \\
\text { in young females }\end{array}$ \\
\hline IPF & Greater prevalence in males & $\begin{array}{l}\text { Improved post-transplant outcomes, survival in females } \\
\text { Greater symptom burden and worse health-related } \\
\text { quality of life in females }\end{array}$ & No data \\
\hline PAH & Greater prevalence in females & Decreased survival in males (“oestrogen paradox”) & $\begin{array}{l}\text { Sex-related differences in response } \\
\text { to commonly used therapies }\end{array}$ \\
\hline SBD & $\begin{array}{l}\text { Greater prevalence in males; } \\
\text { middle-aged men thought to } \\
\text { be most vulnerable } \\
\text { Diagnostic bias in favour of } \\
\text { males }\end{array}$ & $\begin{array}{l}\text { Differing symptoms between males and females } \\
\text { Greater severity in males } \\
\text { Susceptibility may increase in females with obesity, } \\
\text { pregnancy, menopause; maternal SBD may impact } \\
\text { neonatal outcomes }\end{array}$ & No data \\
\hline
\end{tabular}

COPD: chronic obstructive pulmonary disease; CF: cystic fibrosis; IPF: interstitial pulmonary fibrosis; NTM: non-tuberculous mycobacteria; P. aeruginosa: Pseudomonas aeruginosa; PAH: pulmonary arterial hypertension; SBD: sleep-related breathing disorders.

\section{COVID-19}

The COVID-19 pandemic is an unprecedented event that began in late 2019 caused by SARS-CoV-2 and has led to more than 152 million cases and 3.2 million deaths worldwide to date [203]. Although not a chronic lung disease, the evident sex differences in outcomes in COVID19 illustrate clearly the potential for sex to modify lung inflammation and disease outcomes with relevance beyond the current pandemic. International reports suggest that case numbers are similar between males and females, but SARS-CoV-2 severity, which is measured by need for hospitalisation, admission to intensive care, need for mechanical ventilation and death, has been greater in males by 1.5- to 2-fold compared to females across the globe [204-207], excepting a few countries (i.e. India, Nepal, Vietnam, Slovenia) with greater fatality rates in females [208, 209]. These findings largely suggest that biological sex may be playing a protective role in females wherein they exhibit an enhanced response to the acute SARS-CoV-2 infection compared to males [210]. In contrast, gender-related risks of exposure may be affecting the rates of infection in women and men differentially by age group [8, 211]. Mouse models of SARS-CoV-1 have previously demonstrated greater pulmonary damage and death in male compared to female mice [212]. From the pandemic, the "long COVID" syndrome has emerged and is characterised by a range of symptoms persisting weeks to months beyond the initial illness [213]. A prospective study of 4182 incident COVID-19 cases by self-report suggested that $13.3 \%$ had symptoms lasting longer than 28 days and persistent symptoms were more likely with increasing age, BMI, and female sex [214]. Others have identified that those with greater severity of initial infection are at increased risk of long-term complications [215], and organ dysfunction has been identified even in younger individuals following infection [216]. All this highlights that we are merely on the surface of understanding the consequences of COVID-19 and it presents a unique opportunity to evaluate the related sex and gender effects as we move through this pandemic as a global community.

\section{A way forward}

\section{Clinical considerations}

Despite the data on differences, current medical practice does not sufficiently take sex and gender into account in diagnosis, treatment or disease management. As evidence for sex- and gender-based differences 
for disease processes accrues, these should be incorporated into practice guidelines that are published in relevant journals and implemented into clinical care [8]. Extending this further, healthcare programmes (medical, nursing) and allied healthcare (e.g. respiratory therapist, physical therapist) curricula should incorporate sex- and gender-based aspects as practice is shaped by training [217].

\section{Research considerations}

Despite the increasing awareness and efforts, there remains significant sex and gender disparities in clinical studies leading to an incomplete understanding of disease [218]. In clinical trials, although we may see sex-stratified results, the efforts to consider gender and sex as it may relate to efficacy and safety of therapeutics remains limited. Inclusion of a gender dimension to these clinical studies will contribute to greater understanding of disease manifestations and outcomes in males and females [219]. Sex and gender aspects and their inter-relations need to be considered in all aspects of the research process. When sexand/or gender-specific differences are identified in pilot studies, clinical trials (therapies, devices etc.) should be sufficiently powered to evaluate these endpoints, be it related to safety or efficacy. Conscientious recruitment strategies at an early study or trial stage and in line with the study design can help to have equitable enrolment by sex and gender as well as assist with downstream late-phase trials. Given our movement towards personalised and precision-based medicine, sex and gender equity in studies will go a long way towards reaching this goal. Alongside investigators, similar efforts must be put in by academic institutions, pharmaceutical and bio-engineering companies, publishers, as well as policy makers such that we can innovate our current research paradigm and advance together.

\section{Conclusion}

Sex and gender influence chronic lung diseases at all levels, from the pathophysiology and presentation to care received and response to treatment. As we have entered the era of precision medicine, sex and gender are foundationally important in the delivery of care. Given the morbidity and mortality attributable to chronic lung diseases globally, and the increased awareness of how sex and gender can impact disease lived and treated throughout the lifespan, it is imperative that we consider these factors in research and clinical practice. Prospective evaluation of the current global pandemic provides a unique opportunity to better understand sex and gender issues and may serve as a template that can be applied to other disease arenas. It is only through a concerted effort at all invested societal levels that we can promote sex and gender equity in health and improve outcomes.

Provenance: Commissioned article, peer reviewed.

Previous articles in this series: No. 1: Cheron C, McBride SA, Antigny F, et al. Sex and gender in pulmonary arterial hypertension. Eur Respir Rev 2021; 30: 200330. No. 2: LoMauro A, Aliverti A. Sex and gender in respiratory physiology. Eur Respir Rev 2021; 30: 210038. No 3: Chowdhury NU, Guntur VP, Newcomb DC, et al. Sex and gender in asthma. Eur Respir Rev 2021; 30: 210067. No 4: Kawano-Dourado L, Glassberg MK, Assayag D, et al. Sex and gender in interstitial lung diseases. Eur Respir Rev 2021; 30: 210105. No 5: Dominelli PB, Molgat-Seon Y. Sex, gender and the pulmonary physiology of exercise. Eur Respir Rev 2022; 31: 210074. No 6: Ragavan M, Patel MI. The evolving landscape of sex-based differences in lung cancer: a distinct disease in women. Eur Respir Rev 2022; 31: 210100.

Conflict of interest: R. Somayaji has nothing to disclose. J.D. Chalmers has received research grants from AstraZeneca, Boehringer Ingelheim, GlaxoSmithKline, Gilead Sciences, Novartis and Insmed; and received consultancy or speaker fees from AstraZeneca, Boehringer Ingelheim, Chiesi, GlaxoSmithKline, Insmed, Janssen, Novartis and Zambon, outside the submitted work.

\section{References}

1 Clayton J. Studying both sexes: a guiding principle for biomedicine. FASEB J 2016; 30: 519-524.

$2 \quad$ Putting gender on the agenda. Nature 2010; 465: 665.

3 Doyal L. Sex, gender and health: the need for a new approach. BMJ 2001; 323: 1061-1063.

$4 \quad$ Fletcher C, Peto R. The natural history of chronic airflow obstruction. BMJ 1977; 1: 1645-1648.

5 Carey MA, Card JW, Voltz JW, et al. It's all about sex: gender, lung development and lung disease. Trends Endocrinol Metab 2007; 18: 308-313.

6 Townsend E, Miller V, Prakash Y. Sex differences and sex steroids in lung health and disease. Endocr Rev 2012; 33: 1-47.

7 Becklake M, Kauffmann F. Gender differences in airway behaviour over the human life span. Thorax 1999; 54: 1119-1138. 
Mauvais-Jarvis F, Merz N, Barnes PJ, et al. Sex and gender: modifiers of health, disease and medicine. Lancet 2020; 396: 565-582.

Global Health 50/50. Gender and global health. https://globalhealth5050.org/gender-and-global-health/. Date last accessed: 10 January 2021.

Shannon G, Jansen M, Williams K, et al. Gender equality in science, medicine, and global health: where are we at and why does it matter? Lancet 2019; 393: 560-569.

Assari S, Lankarani M, Piette J, et al. Self-rated health and glycemic control in type 2 diabetes: race by gender differences. J Racial Ethn Health Disparities 2018; 5: 721-727.

Assari S, Lankarani M, Burgard S. Black-white difference in long-term predictive power of self-rated health on all-cause mortality in United States. Ann Epidemiol 2016; 26: 106-114.

Kanchi R, Perlman S, Chernov C, et al. Gender and race disparities in cardiovascular disease risk factors among New York City adults: New York City Health and Nutrition Examination Survey (NYC HANES) 20132014. J Urban Health 2018; 95: 801-812.

Pelletier R, Ditto B, Pilote L. A composite measure of gender and its association with risk factors in patients with premature acute coronary syndrome. Psychosom Med 2015; 77: 517-526.

Pelletier R, Choi J, Winters N, et al. Sex differences in clinical outcomes after premature acute coronary syndrome. Can J Cardiol 2016; 32: 1447-1453.

Phillips S. Defining and measuring gender: a social determinant of health whose time has come. Int J Equity Health 2005; 4: 11.

Johnson J, Greaves L, Repta R. Better science with sex and gender: facilitating the use of a sex and gender-based analysis in health research. Int J Equity Health 2009; 8: 14.

GBD Chronic Respiratory Disease Collaborators. Prevalence and attributable health burden of chronic respiratory disease, 1990-2017: a systematic analysis for the Global Burden of Disease Study 2017. Lancet Respir Med 2020; 8: 585-596.

Heron M. Deaths: leading causes for 2017. Natl Vital Stat Rep 2019; 68: 1-77.

Taveira-DaSilva A, Moss J. Optimizing treatments for lymphangioleiomyomatosis. Expert Rev Respir Med 2012; 6: 267-276.

Raghu G, Chen S, Yeh W, et al. Idiopathic pulmonary fibrosis in US Medicare beneficiaries aged 65 years and older: incidence, prevalence and survival, 2001-11. Lancet Respir Med 2014; 2: 566-572.

Badesch D, Raskob G, Elliott C, et al. Pulmonary arterial hypertension: baseline characteristics from the REVEAL registry. Chest 2010; 137: 376-387.

Thenappan T, Shah S, Rich S, et al. A USA-based registry for pulmonary arterial hypertension: 1982-2006. Eur Respir J 2007; 30: 1103-1110.

Vink N, Postma DS, Schouten J, et al. Gender differences in asthma development and remission during transition through puberty: the TRacking Adolescents' Individual Lives Survey (TRAILS) study. J Allergy Clin Immunol 2010; 126: 498-504.

Gottleib S, Zeller M. A nicotine-focused framework for public health. N Engl J Med 2017; 377: 1111-1114.

Hastings M, Reddy A, Maywood E. A clockwork web: circadian timing in brain and periphery, in health and disease. Nat Rev Neurosci 2003; 4: 649-661.

Santhi N, Lazar A, McCabe P, et al. Sex differences in the circadian regulation of sleep and waking cognition in humans. Proc Natl Acad Scie USA 2016; 113: E2730-E2739.

Han M, Arteaga-Solis E, Blenis J, et al. Joint NHLBI-ORWH-ORDR workshop. Female sex and gender in lung/ sleep health and disease. Increased understanding of basic biological, pathophysiological, and behavioral mechanisms leading to better health for female patients with lung disease. Am J Respir Crit Care Med 2018; 198: 850-858.

Barnes PJ. Sex differences in chronic obstructive pulmonary disease mechanisms. Am J Respir Crit Care Med, 2016: 813-814.

Flenley D. Chronic obstructive pulmonary disease. Dis Mon 1988; 34: 537-599.

Han MK, Postma D, Mannino DM, et al. Gender and chronic obstructive pulmonary disease: why it matters. Am J Respir Crit Care Med 2007: 1179-1184.

Schirnhofer L, Lamprecht B, Vollmer WM, et al. COPD prevalence in Salzburg, Austria: results from the Burden of Obstructive Lung Disease (BOLD) study. Chest 2007; 131: 29-36.

Sørheim I-C, Johannessen A, Gulsvik A, et al. Gender differences in COPD: are women more susceptible to smoking effects than men? Thorax 2010; 65: 480-485.

Salvi SS, Barnes PJ. Chronic obstructive pulmonary disease in non-smokers. Lancet 2009; 374: 733-743.

Meghji J, Nadeau G, Davis K, et al. Noncommunicable lung disease in Sub-Saharan Africa. A communitybased cross-sectional study of adults in urban Malawi. Am J Respir Crit Care Med 2016; 194: 67-76.

Gordon S, Bruce N, Grigg J, et al. Respiratory risks from household air pollution in low and middle income countries. Lancet Respir Med 2014; 2: 823-860.

Lamprecht B, McBurnie MA, Vollmer WM, et al. COPD in never smokers: results from the population-based burden of obstructive lung disease study. Chest 2011; 139: 752-763. 
Chapman KR, Tashkin DP, Pye DJ. Gender bias in the diagnosis of COPD. Chest 2001; 119: 1691-1695.

Silverman EK, Weiss ST, Drazen JM, et al. Gender-related differences in severe, early-onset chronic obstructive pulmonary disease. Am J Respir Crit Care Med 2000; 162: 2152-2158.

Miravitlles M, de la Roza C, Naberan K, et al. Attitudes toward the diagnosis of chronic obstructive pulmonary disease in primary care. Archivos de Bronconeumologia 2006; 42: 3-8.

Watson L, Vestbo J, Postma DS, et al. Gender differences in the management and experience of Chronic Obstructive Pulmonary Disease. Respir Med 2004; 98: 1207-1213.

Prescott E, Bjerg AM, Andersen PK, et al. Gender difference in smoking effects on lung function and risk of hospitalization for COPD: results from a Danish longitudinal population study. Eur Respir J 1997; 10: 822-827.

Allen-Ramey FC, Gupta S, DiBonaventura MD. Patient characteristics, treatment patterns, and health outcomes among COPD phenotypes. Int J Chron Obstruct Pulmon Dis 2012; 7: 779-787.

Gan WQ, Man SFP, Postma DS, et al. Female smokers beyond the perimenopausal period are at increased risk of chronic obstructive pulmonary disease: a systematic review and meta-analysis. Respir Res 2006; 7: 52.

Coxson HO, Dirksen A, Edwards LD, et al. The presence and progression of emphysema in COPD as determined by CT scanning and biomarker expression: a prospective analysis from the ECLIPSE study. Lancet Respir Med 2013; 1: 129-136.

Dransfield MT, Washko GR, Foreman MG, et al. Gender differences in the severity of CT emphysema in COPD. Chest 2007; 132: 464-470.

Martinez FJ, Curtis JL, Sciurba F, et al. Sex differences in severe pulmonary emphysema. Am J Respir Crit Care Med 2007; 176: 243-252.

Laurin C, Lavoie KL, Bacon SL, et al. Sex differences in the prevalence of psychiatric disorders and psychological distress in patients with COPD. Chest 2007; 132: 148-155.

Hanania NA, Müllerova H, Locantore NW, et al. Determinants of depression in the ECLIPSE chronic obstructive pulmonary disease cohort. Am J Respir Crit Care Med 2011; 183: 604-611.

Jiménez-Ruiz CA, Andreas S, Lewis KE, et al. Statement on smoking cessation in COPD and other pulmonary diseases and in smokers with comorbidities who find it difficult to quit. Eur Respir J 2015; 46: 61-79.

Tam A, Churg A, Wright JL, et al. Sex differences in airway remodeling in a mouse model of chronic obstructive pulmonary disease. Am J Respir Crit Care Med 2016; 193: 825-834.

Morrell N, Aldred M, Chung W, et al. Genetics and genomics of pulmonary arterial hypertension. Eur Respir J 2019; 53: 1801899.

van der Plaat DA, Pereira M, Pesce G, et al. Age at menopause and lung function: a Mendelian randomisation study. Eur Respir J 2019; 54: 1802421.

Lenoir A, Fuertes E, Gómez-Real F, et al. Lung function changes over 8 years and testosterone markers in both sexes: UK Biobank. ERJ Open Res 2020; 6: 00070-2020.

Foreman MG, Zhang L, Murphy J, et al. Early-onset chronic obstructive pulmonary disease is associated with female sex, maternal factors, and African American race in the COPDGene study. Am J Respir Crit Care Med 2011; 184: 414-420.

Kohler M, Sandberg A, Kjellqvist S, et al. Gender differences in the bronchoalveolar lavage cell proteome of patients with chronic obstructive pulmonary disease. J Allergy Clin Immunol 2013; 131: 743-751.

Vestbo J, Grigg J, Pisinger C, et al. World No Tobacco Day: smoking, nicotine and children. Eur Respir J 2020; 55: 2001633.

Pisinger C, Dagli E, Filippidis FT, et al. ERS and tobacco harm reduction. Eur Respir J 2019; 54: 1902009.

Singh D, Agusti A, Anzueto A, et al. Global strategy for the diagnosis, management and prevention of chronic obstructive lung disease: the GOLD science committee report 2019. Eur Respir J 2019; 53: 1900164.

Wedzicha JA, Singh D, Tsiligianni I, et al. Treatment response to indacaterol/glycopyrronium versus salmeterol/fluticasone in exacerbating COPD patients by gender: a post-hoc analysis in the FLAME study. Respir Res 2019; 20: 4.

Chalmers JD, Miravitlles M. Withdrawal of inhaled corticosteroids in COPD. Eur Respir J 2020; 56: 2001778.

Li X, Obeidat M, Zhou G, et al. Responsiveness to ipratropium bromide in male and female patients with mild to moderate chronic obstructive pulmonary disease. EBioMedicine 2017; 19: 139-145.

Tsiligianni I, Mezzi K, Fucile S, et al. Response to Indacaterol/Glycopyrronium (IND/GLY) by sex in patients with COPD: a pooled analysis from the IGNITE program. COPD 2017; 14: 375-381.

Han MK, Tayob N, Murray S, et al. Predictors of chronic obstructive pulmonary disease exacerbation reduction in response to daily azithromycin therapy. Am J Respir Crit Care Med 2014; 189: 1503-1508.

65 Robles PG, Brooks D, Goldstein R, et al. Gender-associated differences in pulmonary rehabilitation outcomes in people with chronic obstructive pulmonary disease: a systematic review. J Cardiopulm Rehabil Prev 2014; 34: 87-97.

Kynyk JA, Mastronarde JG, McCallister JW. Asthma, the sex difference. Curr Opin Pulm Med 2011; 17: 6-11. Postma D. Gender differences in asthma development and progression. Gend Med 2007; 4: S133-S146. 
Centers for Disease Control and Prevention. Most Recent Asthma Data. https://www.cdc.gov/asthma/most recent_national_asthma_data.htm Date last accessed: 17 September 2021. Date last updated: 2019.

Chen $\mathrm{Y}$, Stewart $\mathrm{P}$, Johansen $\mathrm{H}$, et al. Sex difference in hospitalization due to asthma in relation to age. J Clin Epidemiol 2003; 56: 180-187.

Hyndman SJ, Williams DR, Merrill SL, et al. Rates of admission to hospital for asthma. BMJ 1994; 308: 1596-1600.

Skobeloff EM, Spivey WH, St Clair SS, et al. The influence of age and sex on asthma admissions. JAMA 1992; 268: 3437-3440.

Castro-Rodriguez JA. A new childhood asthma phenotype: obese with early menarche. Paediatr Respir Rev 2016; 18: 85-89.

Troisi RJ, Speizer FE, Willett WC, et al. Menopause, postmenopausal estrogen preparations, and the risk of adult-onset asthma. A prospective cohort study. Am J Respir Crit Care Med 1995; 152: 1183-1188.

Real FG, Svanes C, Omenaas ER, et al. Lung function, respiratory symptoms, and the menopausal transition. J Allergy Clin Immunol 2008; 121: 72-80.e3.

Brenner BE, Holmes TM, Mazal B, et al. Relation between phase of the menstrual cycle and asthma presentations in the emergency department. Thorax 2005; 60: 806-809.

Rao CK, Moore CG, Bleecker E, et al. Characteristics of perimenstrual asthma and its relation to asthma severity and control: data from the Severe Asthma Research Program. Chest 2013; 143: 984-992.

Shames RS, Heilbron DC, Janson SL, et al. Clinical differences among women with and without self-reported perimenstrual asthma. Ann Allergy Asthma Immunol 1998; 81: 65-72.

Oguzulgen IK, Turktas H, Erbas D. Airway inflammation in premenstrual asthma. J Asthma 2002; 39: 517-522. Nwaru BI, Tibble H, Shah SA, et al. Hormonal contraception and the risk of severe asthma exacerbation: 17-year population-based cohort study. Thorax 2021; 76: 109LP-15.

Schatz M, Harden K, Forsythe A, et al. The course of asthma during pregnancy, post partum, and with successive pregnancies: a prospective analysis. J Allergy Clin Immunol 1988; 81: 509-517.

Schatz M, Dombrowski MP, Wise R, et al. Asthma morbidity during pregnancy can be predicted by severity classification. J Allergy Clin Immunol 2003; 112: 283-288.

Holguin F, Cardet JC, Chung KF, et al. Management of severe asthma: a European Respiratory Society/ American Thoracic Society guideline. Eur Respir J 2020; 55: 1900588.

Boulet L-P, Reddel HK, Bateman E, et al. The Global Initiative for Asthma (GINA): 25 years later. Eur Respir $J$ 2019; 54: 1900598.

van Bragt JJMH, Adcock IM, Bel EHD, et al. Characteristics and treatment regimens across ERS SHARP severe asthma registries. Eur Respir J 2019; 54: Suppl. 63, OA5354.

Brightling C, Greening N. Airway inflammation in COPD: progress to precision medicine. Eur Respir J 2019; 54: 1900651.

Card JW, Carey MA, Bradbury JA, et al. Gender differences in murine airway responsiveness and lipopolysaccharide-induced inflammation. J Immunol 2006; 177: 621-630.

Card JW, Voltz JW, Ferguson CD, et al. Male sex hormones promote vagally mediated reflex airway responsiveness to cholinergic stimulation. Am J Physiol Lung Cell Mol Physiol 2007; 292: L908-L914.

Busse WW, Kraft M, Rabe KF, et al. Understanding the key issues in the treatment of uncontrolled persistent asthma with type 2 inflammation. Eur Respir J 2021; 58: 2003393.

Pavlidis S, Takahashi K, Ng Kee Kwong F, et al. "T2-high" in severe asthma related to blood eosinophil, exhaled nitric oxide and serum periostin. Eur Respir J 2019; 53: 1800938.

Riffo-Vasquez Y, Ligeiro de Oliveira AP, Page CP, et al. Role of sex hormones in allergic inflammation in mice. Clin Exp Allergy 2007; 37: 459-470.

Yu C-K, Liu Y-H, Chen C-L. Dehydroepiandrosterone attenuates allergic airway inflammation in Dermatophagoides farinae-sensitized mice. J Microbiol Immunol 2002; 35: 199-202.

Hayashi T, Adachi Y, Hasegawa $\mathrm{K}$, et al. Less sensitivity for late airway inflammation in males than females in BALB/c mice. Scand J Immunol 2003; 57: 562-567.

Takeda M, Tanabe M, Ito W, et al. Gender difference in allergic airway remodelling and immunoglobulin production in mouse model of asthma. Respirology 2013; 18: 797-806.

Blacquière MJ, Hylkema MN, Postma DS, et al. Airway inflammation and remodeling in two mouse models of asthma: comparison of males and females. Int Arch Allergy Immunol 2010; 153: 173-181.

Warren KJ, Sweeter JM, Pavlik JA, et al. Sex differences in activation of lung-related type 2 innate lymphoid cells in experimental asthma. Ann Allergy Asthma Immunol 2017; 118: 233-234.

Melgert BN, Oriss TB, Qi Z, et al. Macrophages: regulators of sex differences in asthma? Am J Respir Cell Mol Biol 2010; 42: 595-603.

Newcomb DC, Peebles RSJ. Th17-mediated inflammation in asthma. Curr Opin Immunol 2013; 25: 755-760. Newcomb DC, Cephus JY, Boswell MG, et al. Estrogen and progesterone decrease let-7f microRNA expression and increase IL-23/IL-23 receptor signaling and IL-17A production in patients with severe asthma. $J$ Allergy Clin Immunol 2015; 136: 1025-1034.e11. 
Ullah MA, Revez JA, Loh Z, et al. Allergen-induced IL- 6 trans-signaling activates $\gamma \delta$ T cells to promote type 2 and type 17 airway inflammation. J Allergy Clin Immunol 2015; 136: 1065-1073.

100 Mao D, Tang R, Wu R, et al. Prevalence trends in the characteristics of patients with allergic asthma in Beijing, 1994 to 2014. Medicine 2017; 96: e7077.

101 Akinbami LJ, Moorman JE, Bailey C, et al. Trends in asthma prevalence, health care use, and mortality in the United States, 2001-2010. NCHS Data Brief 2012: 1-8.

102 Yang F, Busby J, Heaney LG, et al. Factors associated with frequent exacerbations in the UK Severe Asthma Registry. J Allergy Clin Immunol Pract 2021; 9: 2691-2701.

103 Mason R. Pathogenesis of COVID-19 from a cell biology perspective. Eur Respir J 2020; 55: 2000607.

104 Yan D, Liu X-Y, Zhu Y-N, et al. Factors associated with prolonged viral shedding and impact of lopinavir/ ritonavir treatment in hospitalized non-critically ill patients with SARS-CoV-2 infection. Eur Respir J 2020; 56: 2000799.

105 Fan G, Tu C, Zhou F, et al. Comparison of severity scores for COVID-19 patients with pneumonia: a retrospective study. Eur Respir J 2020; 56: 2002113.

106 Beurnier A, Jutant E-M, Jevnikar M, et al. Characteristics and outcomes of asthmatic patients with COVID-19 pneumonia who require hospitalisation. Eur Respir J 2020; 56: 2001875.

107 Harvey ES, Langton D, Katelaris C, et al. Mepolizumab effectiveness and identification of super-responders in severe asthma. Eur Respir J 2020; 55: 1902420.

108 Senna G, Latorre M, Bugiani M, et al. Sex differences in severe asthma: results from severe asthma network in Italy-SANI. Allergy Asthma Immunol Res 2021; 13: 219-228.

109 Haldar P, Pavord ID, Shaw DE, et al. Cluster analysis and clinical asthma phenotypes. Am J Respir Crit Care Med 2008; 178: 218-224.

110 Agusti A, Bel EHD, Thomas M, et al. Treatable traits: toward precision medicine of chronic airway diseases. Eur Respir J 2016; 47: 410-419.

111 Chalmers JD, Aliberti S, Polverino E, et al. The EMBARC European bronchiectasis registry: protocol for an international observational study. ERJ Open Res 2016; 2: 00081-2015.

112 Chalmers JD, Cipolla D, Thompson B, et al. Changes in respiratory symptoms during 48 weeks treatment with ARD-3150 (inhaled liposomal ciprofloxacin) in bronchiectasis: results from the ORBIT-3 and -4 studies. Eur Respir J 2020; 56: 2000110.

113 McDonnell M, Aliberti S, Goeminne P, et al. Comorbidities and the risk of mortality in patients with bronchiectasis: an international multicentre cohort study. Lancet Respir Med 2016; 4: 969-979.

114 Aksamit T, O'Donnell A, Barker A, et al. Adult patients with bronchiectasis: a first look at the US bronchiectasis research registry. Chest 2017; 151: 982-992.

115 Lonni S, Chalmers JD, Goeminne P, et al. Etiology of non-cystic fibrosis bronchiectasis in adults and its correlation to disease severity. Ann Am Thorac Soc 2015; 12: 1767-1770.

116 Gao Y-H, Guan W-J, Xu G, et al. The role of viral infection in pulmonary exacerbations of bronchiectasis in adults: a prospective study. Chest 2015; 147: 1635-1643.

117 King P, Freezer N, Holmes P, et al. Role of CFTR mutations in adult bronchiectasis. Thorax 2004; 59: 357-358.

118 Lanza F, Castro R, de Camargo A, et al. COPD assessment test (CAT) is a valid and simple tool to measure the impact of bronchiectasis on affected patients. COPD 2018; 15: 512-519.

119 Sibila O, Perea L, Canto E, et al. Antimicrobial peptides, disease severity and exacerbations in bronchiectasis. Thorax 2019; 74: 835-842.

120 Visser S, Bye P, Fox G, et al. Australian adults with bronchiectasis: The first report from the Australian bronchiectasis registry. Respir Med 2019; 155: 97-103.

121 Araujo D, Shteinberg M, Aliberti S, et al. Standardised classification of the aetiology of bronchiectasis using an objective algorithm. Eur Respir J 2017; 50: 1701289.

122 Dhar R, Singh S, Talwar D, et al. Bronchiectasis in India: results from the European Multicenter Bronchiectasis Audit and Research Collaboration (EMBARC) and Respiratory Research Network of India Registry. Lancet Glob Health 2019; 7: e1269-e1279.

123 Horton K, MacPherson P, Houben R, et al. Sex differences in tuberculosis burden and notifications in low- and middle-income countries: a systematic review and meta-analysis. PloS Med 2016; 13: e1001219.

124 Shteinberg M, Flume P, Chalmers JD. Is bronchiectasis really a disease? Eur Respir Rev 2020; 29: 190051.

125 Winthrop K, McNelley E, Kendall B, et al. Pulmonary nontuberculous mycobacterial disease prevalence and clinical features: an emerging public health disease. Am J Respir Crit Care Med 2010; 182: 977-982.

126 Quint J, Millett E, Joshi M, et al. Changes in the incidence, prevalence and mortality of bronchiectasis in the UK from 2004 to 2013: a population-based cohort study. Eur Respir J 2016; 47: 186-193.

127 Henkle E, Chan B, Curtis J, et al. Bronchiectasis patient characteristics and healthcare utilization history in US Medicare enrollees with prescription drug plans, 2006-2014. Chest 2018; 154: 1311-1320.

128 Vidaillac C, Yong V, Jaggi T, et al. Gender differences in bronchiectasis: a real issue? Breathe 2018; 14: 108-121.

129 Goutaki M, Crowley S, Dehlink E, et al. The BEAT-PCD (Better Experimental Approaches to Treat Primary Ciliary Dyskinesia) Clinical Research Collaboration. Eur Respir J 2021; 57: 2004601. 
Shoemark A, Rubbo B, Legendre M, et al. Topological data analysis reveals genotype-phenotype relationships in primary ciliary dyskinesia. Eur Respir J 2021; 58: 2002359.

Corey M, Farewell V. Determinants of mortality from cystic fibrosis in Canada, 1970-1989. Am J Epidemiol 1996; 143: 1007-1017.

Fitzsimmons S. The changing epidemiology of cystic fibrosis. J Pediatr 1993; 122: 1-9.

Liou T, Adler F, Fitzsimmons S, et al. Predictive 5-year surviorship model of cystic fibrosis. Am J Epidemiol 2001; 153: 345-352.

Healey N. The gender gap in cystic fibrosis. Nature 2020; 583: S10-S11.

Rosenfeld M, Davis R, FistzSimmons S, et al. Gender gap in cystic fibrosis mortality. Am J Epidemiol 1997; 145: 794-803.

Harness-Brumley C, Elliott A, Rosenbluth D, et al. Gender differences in outcomes of patients with cystic fibrosis. J Women's Health 2014; 23: 1012-1020.

Viviani L, Bossi A, Assael B. Absence of a gender gap in survival. An analysis of the Italian registry for cystic fibrosis in the pediatric age. $J$ Cyst Fibros 2011; 10: 313-317.

Assael B, Castellani C, Ocampo M, et al. Epidemiology and survival analysis of cystic fibrosis in an area of intense neonatal screening over 30 years. Am J Epidemiol 2002; 156: 397-401.

Nick J, Chacon C, Brayshaw S, et al. Effects of gender and age at diagnosis on disease progression in long-term surviors of cystic fibrosis. Am J Respir Crit Care Med 2010; 182: 614-626.

Verma N, Bush A, Buchdahl R. Is there still a gender gap in cystic fibrosis? Chest 2005; 128: 2824-2834.

Finch S, Polverino E, Blasi F, et al. Sex differences in bronchiectasis patient characteristics: an analysis of the EMBARC cohort. Eur Respir J 2018; 52: Suppl. 62, PA2282.

Finch S, Shoemark A, Dicker A, et al. Pregnancy zone protein is associated with airway infection, neutrophil extracellular trap formation, and disease severity in bronchiectasis. Am J Respir Crit Care Med 2019; 200: 992-1001.

Crichton ML, Dudgeon EK, Shoemark A, et al. Validation of the bronchiectasis impact measure (BIM) - a novel patient reported outcome measure. Eur Respir J 2020; 57: 2003156.

Guan W-J, Gao Y-H, Xu G, et al. Capsaicin cough sensitivity and the association with clinical parameters in bronchiectasis. PloS One 2014; 9: e113057.

Özgün Niksarlioglu EY, Özkan G, Günlüoğlu G, et al. Factors related to depression and anxiety in adults with bronchiectasis. Neuropsychiatr Dis Treat 2016; 12: 3005-3010.

Ryu Y, Chun E-M, Lee J, et al. Prevalence of depression and anxiety in outpatients with chronic airway lung disease. Korean J Intern Med 2010; 25: 51-57.

Polverino E, Dimakou K, Hurst J, et al. The overlap between bronchiectasis and chronic airway diseases: state of the art and future directions. Eur Respir J 2018; 52: 1800328.

Demko C, Byard P, Davis P. Gender differences in cystic fibrosis: Pseudomonas aeruginosa infection. J Clin Epidemiol 1995; 48: 1041-1049.

Chotirmall S, Smith S, Gunaratnam C, et al. Effect of estrogen on pseudomonas mucoidy and exacerbations in cystic fibrosis. N Engl J Med 2012; 366: 1978-1986.

Tyrell J, Harvey B. Sexual dimorphism in the microbiolgy of the CF "gender gap": estrogen modulation of Pseudomonas aeruginosa virulence. Steroids 2020; 156: 108575.

study of a distinct preexisting syndrome. Am J Respir Crit Care Med 2008; 178: 1066-1074.

Mirsaeidi M, Hadid W, Ericsoussi B, et al. Non-tuberculous mycobacterial disease is common in patients with non-cystic fibrosis bronchiectasis. Int J Infect Dis 2013; 17: e1000-e1004.

Tsuyuguchi K, Suzuki K, Matsumoto $\mathrm{H}$, et al. Effect of oestrogen on Mycobacterium avium complex pulmonary infection in mice. Clin Exp Immunol 2001; 123: 428-434.

Singh AK, Schultz BD, Katzenellenbogen JA, et al. Estrogen inhibition of cystic fibrosis transmembrane conductance regulator-mediated chloride secretion. J Pharmacol Exp Ther 2000; 295: 195-204.

Sweezey N, Ghibu F, Gagnon S. Sex hormones regulate CFTR in developing fetal rat lung epithelial cells. Am J Physiol 1997; 272: L844-L851.

Coakley RD, Sun H, Clunes LA, et al. 17beta-Estradiol inhibits Ca2+-dependent homeostasis of airway surface liquid volume in human cystic fibrosis airway epithelia. J Clin Investig 2008; 118: 4025-4035.

Jain R, Ray JM, Pan J-H, et al. Sex hormone-dependent regulation of cilia beat frequency in airway epithelium. Am J Respir Cell Mol Biol 2012; 46: 446-453.

Johannesson M, Ludviksdottir D, Janson C. Lung function changes in relation to menstrual cycle in females with cystic fibrosis. Respir Med 2000; 94: 1043-1046.

Gavali M, Gavali Y, Gadkari J, et al. Influence of menstrual cycle on lung functions in young healthy medical students. Int J Health Biomed 2013; 2: 30-34.

Sutton S, Rosenbluth D, Raghavan D, et al. Effects of puberty on cystic fibrosis related pulmonary exacerbation in women versus men. Pediatric Pulmonol 2014; 49: 28-35. 
161 Schecter M, Quittner A, Konstan M, et al. Long-term effects of pregnancy and motherhood on disease outcomes of women with cystic fibrosis. Ann Am Thorac Soc 2013; 10: 213-219.

162 Goss C, Rubenfeld G, Otto K, et al. The effect of pregnancy on survival in women with cystic fibrosis. Chest 2003; 124: 1460-1468.

163 McMullen A, Pasta D, Frederick P, et al. Impact of pregnancy on women with cystic fibrosis. Chest 2006; 129: 706-711.

164 Wang Y, Cela E, Gagnon S, et al. Estrogen aggravates inflammation in Pseudomonas aeruginosa pneumonia in cystic fibrosis. Respir Res 2010; 11: 166.

165 Chotirmall S, Greene C, Oglesby I, et al. 17Beta-estradiol inhibits IL-8 in cystic fibrosis by up-regulating secretory leucoprotease inhibitor. Am J Respir Crit Care Med 2010; 182: 62-72.

166 Chotirmall S, Greene C, McElvaney N. Immune, inflammatory and infectious consequences of estrogen in women with cystic fibrosis. Expert Rev Respir Med 2012; 6: 573-575.

167 Mooney C, McKiernan P, Raoof P, et al. Plasma microRNA levels in male and female children with cystic fibrosis. Sci Rep 2020; 10: 1141.

168 Middleton $\mathrm{P}$, Mall M, Drevinek $\mathrm{P}$, et al. Elexacaftor-tezacaftor-ivacaftor for cystic fibrosis with a single Phe508del allele. N Engl J Med 2019; 381: 1809-1819.

169 Heijerman J, McKone E, Downey D, et al. Efficacy and safety of the elexacaftor plus tezacaftor plus ivacaftor combination regimen in people with cystic fibrosis homozygous for the F508del mutation: a double-blind, randomized, phase 3 trial. Lancet 2019; 394: 1940-1948.

170 Wolfenden L, Schecter M. Genetic and non-genetic determinants of outcomes in cystic fibrosis. Paediatr Respir Rev 2009; 10: 32-36.

171 Farrell P, Joffe S, Foley L, et al. Diagnosis of cystic fibrosis in the Republic of Ireland: epidemiology and costs. Ir Med J 2007; 100: 557-560.

172 McCormick J, Sims E, Mehta A. Delayed diagnosis of females with respiratory presentation of cystic fibrosis did not segregate with poorer clinical outcomes. J Clin Epidemiol 2006; 59: 315-322.

173 Lai H, Kosorok M, Laxova A, et al. Delayed diagnosis of US females with cystic fibrosis. Am J Epidemiol 2002; 156: 165-173.

174 Milla C, Billings J, Moran A. Diabetes is associated with dramatically decreased survival in female but not male subjects with cystic fibrosis. Diabetes Care 2005; 28: 2141-2144.

175 Waters D, Wilcken B, Irwing L, et al. Clinical outcomes of newborn screening for cystic fibrosis. Arch Dis Child Fetal Neonatal Ed 1999; 80: F1-F7.

176 Farrell P, Kosorok M, Rock M, et al. Wisconsin Cystic Fibrosis Neonatal Screening Study Group. Early diagnosis of cystic fibrosis through neonatal screening prevents severe malnutrition and improves long-term growth. Pediatrics 2001; 107: 1-13.

177 Patterson J, Wall M, Berge J, et al. Gender differences in treatment adherence among youth with cystic fibrosis: development of a new questionnaire. J Cyst Fibros 2008; 7: 154-164.

178 Patterson J, Wall M, Berge J, et al. Association of psychosocial factors with health outcomes among youth with cystic fibrosis. Pediatric Pulmonol 2009; 44: 46-53.

179 Czajkowski D, Koocher G. Medical compliance and coping with cystic fibrosis. J Child Psychol Psychiatry 1987; 28: 311-319.

180 Abbott J, Conway S, Etherington C, et al. Perceived body image and eating behavior in young adults with cystic fibrosis and their healthy peers. J Behav Med 2000; 23: 501-517.

181 Besier T, Schmitz T, Goldbeck L. Life satisfaction of adolescents and adults with cystic fibrosis: impact of partnership and gender. J Cyst Fibros 2009; 8: 104-109.

182 Willis E, Miller R, Wyn J. Gendered embodiment and survival for young people with cystic fibrosis. Soc Sci Med 2001; 53: 1163-1174.

183 Walters S. Sex differences in weight perception and nutritional behavior in adults with cystic fibrosis. $J$ Hum Nutr Diet 2001; 14: 83-91.

184 Arrington-Sanders R, Yi M, Tseviat J, et al. Gender differences in health-related quality of life of adolescents with cystic fibrosis. Health Qual Life Outcomes 2006; 4: 5.

185 Polverino E, Goeminne P, McDonnell M, et al. European Respiratory Society guidelines for the management of adult bronchiectasis. Eur Respir J 2017; 50: 1700629.

186 Laska I, Chalmers JD. Treatment to prevent exacerbations in bronchiectasis: macrolides as first line? Eur Respir J 2019; 54: 1901213.

187 Chalmers JD, Boersma W, Lonergan M, et al. Long-term macrolide antibiotics for the treatment of bronchiectasis in adults: an individual participant data meta-analysis. Lancet Respir Med 2019; 7: 845-854.

188 Bilton D, Tino G, Barker A, et al. Inhaled mannitol for non-cystic fibrosis bronchiectasis: a randomised, controlled trial. Thorax 2014; 69: 1073-1079.

189 Raghu G, Weycker D, Edelsberg J, et al. Incidence and prevalence of idiopathic pulmonary fibrosis. Am J Respir Crit Care Med 2006; 174: 810-816. 
Hutchinson J, Fogarty A, McKeever T, et al. In-hospital mortality after surgical lung biopsy for interstitial lung disease in the United States: 2000 to 2011. Am J Respir Crit Care Med 2016; 193: 1161-1167.

191 Sheikh S, Hayes DJ, Kirkby S, et al. Age-dependent gender disparities in post lung transplant survival among patients with idiopathic pulmonary fibrosis. Ann Thorac Surg 2017; 103: 441-446.

192 Han M, Murray S, Fell C, et al. Sex differences in physiological progression of idiopathic pulmonary fibrosis. Eur Respir J 2008; 31: 1183-1188.

193 Han M, Swigris J, Liu L, et al. Gender influences health-related quality of life in IPF. Respir Med 2010; 104 724-730.

194 Voltz JW, Card JW, Carey MA, et al. Male sex hormones exacerbate lung function impairment after bleomycin-induced pulmonary fibrosis. Am J Respir Cell Mol Biol 2008; 39: 45-52.

195 Lahm T, Tuder R, Petrache I. Progress in solving the sex hormone paradox in pulmonary hypertension. Am J Physiol Lung Cell Mol Physiol 2014; 307: L7-L26.

196 Jacobs W, van de Verrdonk M, Trip P, et al. The right ventricle explains sex differences in survival in idiopathic pulmonary arterial hypertension. Chest 2014; 145: 1230-1236.

197 Olsson K, Delcroix M, Ghofrani H, et al. Anticoagulation and survival in pulmonary arterial hypertension: results from the Comparative, Prospective Registry of Newly Initiated Therapies for Pulmonary Hypertension (COMPERA). Circulation 2014; 129: 57-65.

198 Javaheri S, Barbe F, Campos-Rodriguez F, et al. Sleep apnea: types, mechanisms, and clinical cardiovascular consequences. J Am Coll Cardiol 2017; 69: 841-858.

199 Mallampalli M, Carter C. Exploring sex and gender differences in sleep health: a Society for Women's Health Research Report. J Women's Health 2014; 23: 553-562.

200 Wimms A, Woehrle H, Ketheeswaran S, et al. Obstructive sleep apnea in women: specific issues and interventions. Biomed Res Int 2016; 2016: 1764837.

201 Bin Y, Cistulli P, Ford J. Population-based study of sleep apnea in pregnancy and maternal and infant outcomes. J Clin Sleep Med 2016; 12: 871-877.

202 Chen H, Cade B, Gleason K, et al. Multiethnic meta-analysis identifies RAl1 as a possible obstructive sleep apnea-related quantitative trait locus in men. Am J Respir Cell Mol Biol 2018; 58: 391-401.

203 Johns Hopkins University of Medicine Coronavirus Resource Center. https://coronavirus.jhu.edu/map.html Date last accessed: 10 April 2021.

204 Guan W-J, Ni Z, Hu Y, et al. Clinical characteristics of coronavirus disease 2019 in China. N Engl J Med 2020; 382: 1708-1720.

205 Grasselli G, Zangrillo A, Zanella A, et al. Baseline characteristics and outcomes of 1591 patients infected with SARS-CoV-2 admitted to ICUs of Lombardy region, Italy. JAMA 2020; 1574-1581.

206 Richardson S, Hirsch J, Narasimhan M, et al. Presenting characteristics, comorbidities, and outcomes among 5700 patients hospitalized with COVID-19 in the New York City area. JAMA 2020; 323: 2052-2059.

207 Gebhard C, Regitz-Zagrosek V, Neuhauser H, et al. Impact of sex and gender on COVID-19 outcomes in Europe. Biol Sex Differ 2020; 11: 29.

208 Dehingia N, Raj A. Sex differences in COVID-19 case fatality: do we know enough? Lancet Glob Health 2021; 9: E14-E15.

209 Joe A, Kumar A, Rajpal S, et al. Equal risk, unequal burden? Gender differentials in COVID-19 mortality in India. J Glob Health Sci 2020; 2: e17.

210 Takahashi T, Ellingson M, Wong P, et al. Sex differences in immune responses that underlie COVID-19 disease outcomes. Nature 2020; 588: 315-320.

211 Galasso V, Pons V, Profeta P, et al. Gender differences in COVID-19 attitudes and behavior: panel evidence from eight countries. Proc Natl Acad Sci USA 2020; 117: 27285-27291.

212 Channappanavar R, Fett C, Mack M, et al. Sex-based differences in susceptibility to severe acute respiratory syndrome coronavirus infection. J Immunol 2017; 198: 4046-4053.

213 Centers of Disease Control and Prevention. Post-COVID Conditions. www.cdc.gov/coronavirus/2019-ncov/ long-term-effects.html Date last accessed: 10 April 2021.

214 Sudre C, Murray B, Varsavsky T, et al. Attributes and predictors of long COVID. Nature Medicine 2021; 27: 626-631.

215 Al-Aly Z, Yan X, Bowe B. High-dimensional characterization of post-acute sequelae of COVID-19. Nature 2021; 594: 259-264.

216 Dennis A, Wamil M, Alberts J, et al. Multiorgan impairment in low-risk individuals with post-COVD-19 syndrome: a prospective, community-based study. BMJ Open 2021; 11: e048391.

217 Chin E, Hoggatt M, McGregor A, et al. Sex and gender medical education summit: a roadmap for curricular innovation. Biol Sex Differ 2016; 7: 52.

218 Melloni C, Berger J, Wang T, et al. Representation of women in randomized clinical trials of cardiovascular disease prevention. Circ Cardiovasc Qual Outcomes 2010; 3: 135-142.

219 Regitz-Zagrosek V, Seeland U. Sex and gender differences in clinical medicine. In: Regitz-Zagrosek V, Seeland U, eds. Handbook of Experimental Pharmacology. Heidelberg, Springer, 2012, pp. 3-22. 